\title{
¿Bacterias para la tolerancia analgésica a la morfina?
}

\author{
E. J. Cobos del Moral
}

\author{
Departamento de Farmacología (Facultad de Medicina) e Instituto de Neurociencias, (Centro de \\ Investigación Biomédica]. Universidad de Granada. Instituto de Investigación Biosanitaria ibs. GRANADA. \\ Complejo Hospitalario Universitario de Granada/Universidad de Granada
}

La microbiota es el conjunto de microorganismos que conviven en simbiosis en nuestro cuerpo, y se localiza principalmente en el tracto digestivo. Aproximadamente 150 especies diferentes de bacterias viven en nuestro intestino, y son tan abundantes que suponen aproximadamente un número total de $10^{14}$ microorganismos (en torno a 10 veces más microorganismos que células humanas) $(1,2)$. La microbiota juega un papel importantísimo en la fisiología del individuo, y no solamente en el proceso digestivo. Curiosamente, la microbiota puede modular funciones cerebrales por el llamado eje intestino-cerebro, mediante la comunicación con el mismo a través de la estimulación del nervio vago y de la modulación del sistema inmunitario [2]. Esta comunicación depende de la abundancia relativa del tipo bacteriano concreto. De hecho, se ha demostrado en estudios preclínicos que el cambio en la composición de la microbiota es capaz de influenciar los niveles de BDNF (brain-derived neurotrophic factor, de sus siglas en inglés), GABA, serotonina y dopamina (2). No es de extrañar, por tanto, que cuando se produce un cambio en la composición normal de la microbiota, puedan verse alteradas funciones centrales.

La tolerancia se define como una disminución en la respuesta farmacológica tras la administración repetida o prolongada de medicamentos. Este fenómeno ocurre con los agonistas opioides y conduce al aumento de las dosis requeridas para mantener el mismo nivel de analgesia (3). Sin embargo, la velocidad a la que se desarrolla la tolerancia no es idéntica para todos los efectos opioides. Por ejemplo, la tolerancia a la depresión respiratoria y al estreñimiento en respuesta al tratamiento con opioides se desarrolla mucho más lentamente que a la analgesia $[4,5]$. Como consecuencia, el aumento en la dosis del opioide para mantener una analgesia aceptable produce un aumento notable en los efectos secundarios, con la consecuente dis- minución del índice terapéutico $(4,5)$. Por lo tanto, la tolerancia analgésica es un inconveniente importante del uso de analgésicos opioides.

Hay varios estudios recientes que indican que el uso crónico de opioides en pacientes humanos produce alteraciones profundas en la microbiota, incrementando las bacterias de la familia Prevotellaceae (entre otras] $(6,7)$, aunque su papel en la tolerancia analgésica a los opioides no había sido explorado hasta ahora. Es necesario entender los acontecimientos que conducen a los opioides a producir tolerancia analgésica, para así diseñar estrategias terapéuticas eficaces frente a este problema, para lo cual es imprescindible la realización de estudios preclínicos. En un trabajo publicado recientemente en Proceedings of the National Academy of Sciences of the USA, dirigido por la Profesora Sabita Roy (Universidad de Miami), se ha estudiado la relación entre la microbiota y la tolerancia a la analgesia morfínica en ratones, con resultados sorprendentes (8).

En este trabajo describen que el tratamiento repetido con morfina induce cambios en la microbiota del ratón, incrementando algunas bacterias de la familia Prevotellaceae (entre otras] y produciendo alteraciones en el epitelio intestinal de los ratones, con la formación de infiltrados inflamatorios a nivel de las vellosidades intestinales. Este proceso desemboca en el incremento de la permeabilidad intestinal, de manera que en estas circunstancias las bacterias pueden migrar a los ganglios linfáticos mesentéricos o incluso al hígado, lo cual produce un estado de inflamación sistémica evidenciado por el incremento de varias citoquinas proinflamatorias a varios niveles, incluyendo el cerebro del animal. El trasplante fecal proveniente de animales tratados con morfina a animales sanos (sin tratamiento farmacológico previo alguno] es capaz de producir alteraciones intestinales como si se tratara de un animal bajo tratamiento opioide, indicando que la microbiota modificada 
por el tratamiento con morfina tiene un papel activo en estos acontecimientos que se inician a nivel intestinal.

Uno de los principales hallazgos de este trabajo es que el tratamiento crónico de morfina produce una tolerancia analgésica muy reducida en animales libres de gérmenes (animales libres de cualquier microorganismo], o en animales adultos sometidos a tratamiento antibiótico severo para eliminar la microbiota. Estos datos conducen a pensar que la microbiota tiene un papel negativo en la analgesia inducida por el tratamiento crónico con morfina. Sin embargo, aunque la microbiota en su conjunto pueda promover la tolerancia opioide, teniendo en cuenta la gran diversidad bacteriana de la microbiota, es complicado pensar que todas las bacterias tengan un impacto negativo en este proceso. De hecho, algunas especies bacterianas que forman parte de la microbiota natural del intestino, tales como Bifidobacterium y Lactobacillus, tienen un papel muy positivo manteniendo la integridad del epitelio intestinal (9). Teniendo esto en cuenta, Zhang y cols. administran un preparado probiótico comercial para uso humano, y que contiene varias especies de Bifidobacterium y Lactobacillus, y con esto consiguen atenuar la respuesta inflamatoria sistémica inducida por la morfina, así como la tolerancia analgésica a este opioide. Por lo tanto, en lugar de eliminar la microbiota intestinal para disminuir la tolerancia analgésica a la morfina (lo cual sería sin duda perjudicial en muchos aspectos], basta con enriquecer a la población bacteriana intestinal en especies que contribuyen a la conservación de la integridad del epitelio intestinal.

Es interesante destacar que el impacto de la microbiota en la salud está siendo estudiado recientemente desde muchos frentes diferentes, y hay en marcha varios ensayos clínicos destinados a evaluar el efecto de probióticos en trastornos tales como la migraña, el síndrome de Rett, la esclerosis lateral amiotrófica, la encefalopatía hepática o la epilepsia (10). La belleza de esta estrategia terapéutica es su sencillez y su ausencia de efectos adversos, además de su reducido coste. Por lo tanto, no sería una sorpresa que a raíz de los resultados aquí comentados, se plantee algún ensayo clínico para estudiar la influencia del tratamiento con probióticos en pacientes bajo uso crónico de opioides. Si la administración de probióticos tuviera una repercusión positiva en el mantenimiento de una analgesia aceptable en pacientes bajo tratamiento opioide, se podría disminuir el escalado en la dosis de los mismos para así mantener el índice terapéutico del tratamiento analgésico.
En resumen, aunque queda todavía mucho por descubrir en la relación de la microbiota y la salud, estaremos atentos a los posibles efectos terapéuticos de estos "bichitos del yogur" que parecen tener tantas posibilidades.

\section{BIBLIOGRAFÍA}

1. Kåhrström CT, Pariente N, Weiss U. Intestinal microbiota in health and disease. Nature. 2016;535(7610):47. DOI: 10.1038/535047a.

2. Schroeder BO, Bäckhed F. Signals from the gut microbiota to distant organs in physiology and disease. Nat Med. 2016;22(10):1079-89. DOI: 10.1038/nm.4185.

3. Raehal KM, Schmid CL, Groer CE, Bohn LM. Functional selectivity at the mu-opioid receptor: implications for understanding opioid analgesia and tolerance. Pharmacol Rev. 2011;63:1001-19. DOI: 10.1124/pr.111.004598.

4. Pasternak GW, Pan YX. Mu opioids and their receptors: evolution of a concept. Pharmacol Rev. 2013;65(4):1257317. DOl: 10.1124/pr.112.007138.

5. Hayhurst CJ, Durieux ME. Differential Opioid Tolerance and Opioid-induced Hyperalgesia: A Clinical Reality. Anesthesiology. 2016;124(2):483-8. DOI: 10.1097/ ALN.0000000000000963.

6. Acharya C, Betrapally NS, Gillevet PM, Sterling RK, Akbarali $\mathrm{H}$, White $\mathrm{MB}$, et al. Chronic opioid use is associated with altered gut microbiota and predicts readmissions in patients with cirrhosis. Aliment Pharmacol Ther. 2017;45(2):31931. DOI: 10.1111/apt.13858.

7. Barengolts E, Green SJ, Eisenberg Y, Akbar A, Reddivari B, Layden BT, et al. Gut microbiota varies by opioid use, circulating leptin and oxytocin in African American men with diabetes and high burden of chronic disease. PLoS One. 2018;13(3):e0194171. DOI: 10.1371/journal. pone.0194171.

8. Zhang L, Meng J, Ban Y, Jalodia R, Chupikova I, Fernandez I, et al. Morphine tolerance is attenuated in germfree mice and reversed by probiotics, implicating the role of gut microbiome. Proc Natl Acad Sci U S A. 2019;116(27): 13523-32. DOI: $10.1073 /$ pnas.1901182116.

9. Wang BG, Xu HB, Wei H, Zeng ZL, Xu F. Oral administration of Bifidobacterim bifidum for modulating microflora, acid and bile resistance, and physiological índices in mice. Can $\mathrm{J}$ Microbiol. 2015;61(2):155-63. DOl: 10.1139/cjm-2014-0694.

10. Gomez-Eguilaz M, Ramon-Trapero JL, Perez-Martinez L, Blanco JR. El eje microbiota-intestino-cerebro y sus grandes proyecciones. Rev Neurol. 2019;68(3):111-7. DOI: 10.33588/rn.6803.2018223. 